\title{
Low Noncytotoxic Concentrations of 5-Fluorouracil Have No Adverse Effects on Maturation and Function of Bone Marrow-Derived Dendritic Cells in vitro: A Potentially Safe Adjuvant for Dendritic Cell-Based Cancer Therapy
}

\author{
Afshin Namdar ${ }^{a}$ Hamid Reza Mirzaei ${ }^{b}$ Morteza Hafezic Najmeh Khosravianfarc \\ Nasim Kheshtchin ${ }^{b}$ Reza Mirzaei ${ }^{b}$ Jamshid Hadjatib ${ }^{b}$ Abbas Rezaei $^{a}$ \\ ${ }^{a}$ Department of Immunology, School of Medicine, Isfahan University of Medical Sciences, Isfahan, ${ }^{b}$ Department of \\ Immunology, School of Medicine, and ' Department of Pathobiology, School of Public Health, Tehran University of \\ Medical Sciences, Tehran, Iran
}

\section{Key Words}

Chemotherapeutic drugs · 5 -Fluorouracil ·

Bone marrow-derived dendritic cells · Dendritic cell immunotherapy

\begin{abstract}
Background: Low, noncytotoxic concentrations of various chemotherapeutic drugs like 5-fluorouracil (5-FU) induce antitumor immune responses by selectively depleting tumor-induced immunosuppressive cells, and could therefore be used in combination with dendritic cell (DC) vaccines in order to enhance their immunotherapeutic efficacy. However, the likely negative influences of low, noncytotoxic doses of 5-FU on bone marrow-derived (BM)-DCs in vitro have not yet been investigated. Methods: The effects of low, noncytotoxic concentrations of 5-FU on mouse BM-DC differentiation and maturation markers (CD11C, MHC class II and CD80) as well as antigen-presenting capacity and cytokine production (IL-12p70 and IL-10) have been assessed. Results: Different low doses of 5-FU had no significant effect on the expression of DC differentiation and maturation or on
\end{abstract}

(c) 2015 S. Karger AG, Basel

$1018-2438 / 15 / 1682-0122 \$ 39.50 / 0$ costimulatory markers $(p=0.5)$. Furthermore, suboptimal doses of 5-FU did not affect the immunostimulatory functions of DCs such as antigen presentation $(p=0.6)$ and cytokine production $(p=0.9)$. Conclusions: These data suggest that low doses of 5-FU have no adverse effects on DC maturation and function, and the efficacy of DC-based cancer immunotherapy may be greatly enhanced by combining it with suboptimal doses of 5-FU.

() 2015 S. Karger AG, Basel

\section{Introduction}

Dendritic cell (DC)-based cancer vaccines have long been considered an attractive option in the treatment of cancers [1]. Vaccination strategies involving DCs are well developed due to the essential role of the cells as professional antigen-presenting cells (APCs) in launching tumor-specific $\mathrm{T}$ cell immunity, and also inducing immunological memory in mice and cancer patients [2]. Ex vivo generation of mouse DCs from bone marrow (BM) progenitor cells cultured with various stimulating factors
Correspondence to: Prof. Abbas Rezaei 
have been used to induce antitumor T cell immunity [3], but despite some clinical responses to therapy having been observed, the overall therapeutic results of DC vaccines are mostly unsatisfactory $[4,5]$. It has become apparent that immunosuppressive cells, like myeloidderived suppressor cells (MDSCs), recruited to the tumor site cause the failure of DC vaccine immunotherapy. MDSCs, which multiply and are activated in pathological conditions such as cancer, are defined as a heterogeneous population of immature granulocytes, monocytes/macrophages and DCs. An elevated number of these cells in the tumor environment is strongly correlated with a higher tumor burden and poor antitumor immune responses. Therefore, diminishing MDSCs is a promising therapeutic strategy to reverse cancer-associated immune dysfunction and, thereby, enhance the antitumor effects of DC vaccines [6].

Multiple studies demonstrate that chemotherapeutic drugs, when used at lower-toxicity doses for cancer treatment, are able to induce immune responses against tumors by releasing new antigens and, in the case of some antineoplastic agents, also selectively eliminate immunosuppressor cells [7-12]. 5-Fluorouracil (5-FU), a pyrimidine analog with antimetabolite activity, is one of the chemotherapeutic drugs broadly used for the treatment of several cancers in optimal doses. 5-FU, in low, noncytotoxic concentrations $(50 \mathrm{mg} / \mathrm{kg}$ ), has been found to selectively deplete MDSCs in tumor-bearing mice, and hence, in combination with DC vaccines, it could be used to improve the antitumor effects of these vaccines [13]. Since MDSCs have common precursors with DCs, utilizing 5 -FU concurrently with DC vaccines might have an inhibitory impact on DCs as well as on MDSCs. It is therefore essential to understand whether low concentrations of 5-FU could affect the maturation and immunostimulatory functions of BM-derived DCs (BM-DCs) in vitro.

\section{Materials and Methods}

\section{Mice and Cancer Cell Lines}

Six- to eight-week-old female C57BL/6 and Balb/c mice were purchased from the Animal Center, Pasteur Institute of Tehran, Iran. They were housed in transparent plastic cages, under controlled temperature and humidity and a 12-hour light-dark cycle, with sterile food and water ad libitum.

B16F10 melanoma and 4T1 mouse mammary cancer cell lines were purchased from the Cell Bank of Iran (Pasteur Institute of Tehran, Iran) and cultured in complete RPMI 1640 (Gibco, USA) supplemented with $10 \%$ heat-inactivated fetal bovine serum (FBS), $2 \mathrm{mM}$ L-glutamine, $100 \mu \mathrm{g}$ streptomycin and $100 \mathrm{U} / \mathrm{ml}$ penicillin (Biosera, South Korea).

5-FU Has No Adverse Effects on

Maturation of DCs

\section{Evaluation of Cancer Cell Line Viability}

The effect of various concentrations of 5-FU on the proliferation of cancer cell lines was evaluated using an MTT assay (Sigma, USA). B16F10 melanoma and 4T1 mammary tumor cell lines were seeded separately at $2.5 \times 10^{4}$ /well in 96 -well, flat-bottom plates and incubated overnight. The chemotherapeutic drug 5-FU (Sigma) was dissolved in DMSO and added to the wells for 18 and $24 \mathrm{~h}$ to give final concentrations of 50, 100, 200 and 2,500 $\mu \mathrm{M}$. The wells without 5 -FU for every cell line served as negative controls. At the end of each period, $25 \mu \mathrm{l}$ of MTT solution $(5 \mathrm{mg} / \mathrm{ml})$ was added to the wells and incubated at $37^{\circ} \mathrm{C}$ for $4 \mathrm{~h}$. Cells were then incubated with $100 \mu \mathrm{l}$ of DMSO for $10 \mathrm{~min}$ at room temperature after removing culture media, and the optical density (OD) was measured on a microplate reader (Bio-Tek, UK) at $570 \mathrm{~nm}$. The experiment was repeated at least 3 times in triplicate. The viability percentage of every cell line was calculated using the formula: $\%$ viability $=(\mathrm{OD}$ of $5-\mathrm{FU}$-treated sample/OD of control sample) $\times 100$. The selection of indicated doses of 5 -FU was based on studies that found that concentrations up to $250 \mu \mathrm{M}$ had the least effect on the survival and function of natural killer cells in vitro, but that at higher concentrations $(2,500 \mu \mathrm{M})$, these activities were reduced significantly [14]. Moreover, single, low doses of 5-FU, e.g. $50 \mathrm{mg} / \mathrm{kg}$, which is 20 - to 50 -fold lower than the cytotoxic concentration for the EL4 thymoma cell line in vitro, have no adverse effects on immune cells in thymoma-bearing mice [13].

Cell Line Lysate Preparation, Mouse Immunization and T Cell Separation

The 4T1 cell line lysate was prepared by repeated rounds of freezing and thawing of $10^{7}$ tumor cells $/ \mathrm{ml}$ in liquid nitrogen and a $37^{\circ} \mathrm{C}$ water bath. The concentration of protein in the lysate supernatant was measured by bicinchoninic acid (BCA) assay (Thermo Scientific, USA).

4T1 lysate $(100 \mu \mathrm{g})$ suspended in sterile $200 \mu \mathrm{l}$ PBS was injected subcutaneously into $\mathrm{Balb} / \mathrm{c}$ mice for immunization to give a final concentration of $500 \mu \mathrm{g} / \mathrm{ml}$. Two weeks after immunization, a single-cell suspension was prepared from mechanically dissociated spleen cells. Peripheral blood mononuclear cells were isolated using Ficoll density gradient centrifugation (Lymphodex, InnoTrain, Germany) and T cells were separated from peripheral blood mononuclear cells after incubation for $45 \mathrm{~min}$ on a nylon wool column. More than $70 \%$ of eluted cells were T lymphocytes based on CD3 expression. $1.2 \times 10^{7} \mathrm{~T}$ cells $/ \mathrm{ml}$ were labeled with $2.5 \mu \mathrm{mol} / \mathrm{l}(\mu \mathrm{M})$ fluorescein diacetate succinimidyl diester (CFSE, Molecular Probes, USA) for $15 \mathrm{~min}$ and the reaction was terminated by $5 \mathrm{ml}$ of FBS. The CFSE-labeled T cells were used in a proliferation assay after washing 3 times with RPMI 1640 containing 10\% FBS.

\section{Generation of BM-DCs}

BM-DCs were generated as described by Inaba et al. [15] with slight modifications. Briefly, hematopoietic progenitor cells were isolated from the BM of femurs and tibias of the sacrificed C57BL/ 6 and Balb/c mice. Then cells were suspended $\left(6 \times 10^{5} \mathrm{cells} / \mathrm{ml}\right)$ in complete RPMI 1640 medium containing $5 \mathrm{ng} / \mathrm{ml}$ recombinant GM-CSF (BD Pharmingen, USA) and $10 \mathrm{ng} / \mathrm{ml}$ recombinant IL-4 (Peprotech, USA), plated in 24-well, flat-bottom plates and incubated in $5 \% \mathrm{CO}_{2}$ at $37^{\circ} \mathrm{C}$. On days 3 and 5 , half of the volume of every well was replaced by fresh medium. On day $6,2 \mu \mathrm{g} / \mathrm{ml}$ LPS (Sigma) were added to the wells as a maturation factor. Some wells were left immature and these served as negative controls. Simulta-

Int Arch Allergy Immunol 2015;168:122-130 
neously, 5-FU was added to some wells to give the final abovementioned concentrations. In cultured wells with cells from Balb/c mice, $100 \mu \mathrm{g} / \mathrm{ml}$ of $4 \mathrm{~T} 1$ lysate were added $4 \mathrm{~h}$ before LPS maturation. Eighteen hours after LPS maturation, the supernatants of the 5-FU-treated or untreated mature DCs were collected for further analysis; the DCs were harvested and assessed for viability using trypan blue staining. Harvested mature DCs were maintained in complete RPMI for further experiments.

\section{Flow Cytometric Analysis}

Harvested DCs were incubated with antibodies against PE-labeled mouse anti-CD11c, FITC-labeled mouse anti-IA/IE and PElabeled mouse anti-CD80 (BioLegend, USA) for $20 \mathrm{~min}$ and washed in PBS containing 1\% bovine serum albumin (Sigma) and $0.1 \%$ sodium azide. Cell samples were analyzed using a FACSCalibur flow cytometer (BD Biosciences, USA). The results are expressed as the percentage of positive cells or the mean fluorescence intensity (MFI) against isotype controls. Flow cytometry analyses were done using FlowJo 7.6.1 software.

\section{Antigen-Presenting Capacity}

The antigen-presenting capacity of 5-FU-treated BM-DCs was evaluated as described earlier [16] with slight modifications. Briefly, $10^{5} / \mathrm{ml} \mathrm{CFSE-labeled} \mathrm{T} \mathrm{cells} \mathrm{of} \mathrm{4T1-immunized} \mathrm{mice} \mathrm{were} \mathrm{cul-}$ tured in 24-well, flat-bottom plates in complete RPMI 1640 in the presence of $5 \times 10^{5} / \mathrm{ml}$ harvested $4 \mathrm{~T} 1$ lysate-preloaded BM-DCs treated with indicated doses of 5-FU. Untreated immature and mature DCs cocultured with CFSE-labeled T cells, CFSE-labeled T cells stimulated with $3 \mu \mathrm{l} / \mathrm{ml}$ phytohemaglutinin (Gibco, USA) and unstimulated $\mathrm{T}$ cells served as controls. After incubation at $37^{\circ} \mathrm{C}$ in $5 \% \mathrm{CO}_{2}$ for 5 days, cells were harvested and incubated with APC-conjugated anti-CD3 antibody. CFSE dilution in the CD3 population was analyzed using flow cytometry.

\section{Measurement of Cytokine Production}

The supernatants collected from the 5-FU-treated or untreated mature and immature BM-DCs $\left(6 \times 10^{5}\right.$ cells $\left./ \mathrm{ml}\right)$ were used for the evaluation of IL-12p70 and IL-10 cytokines by ELISA (R\&D Systems, USA) according to the instruction manual.

\section{Statistics}

All statistical analyses were performed by GraphPad Prism 6 software. One-way ANOVA followed by the post hoc Tukey test was performed between multiple groups. The statistical differences were considered significant when the probability error was $<5 \%$ ( $\mathrm{p} \leq 0.05)$. Results were presented as the mean \pm SEM.

\section{Results}

Effects of Low Concentrations of 5-FU on the Viability of BM-DC and Tumor Cell Lines

Initially, mature DC viability was assessed using trypan blue staining. After 18 h of treatment, $>90 \%$ of harvested DCs treated with low concentrations (50, 100 and $200 \mu \mathrm{M})$ of 5-FU survived, which was the same as untreated mature DCs, while the viability of DCs treated with

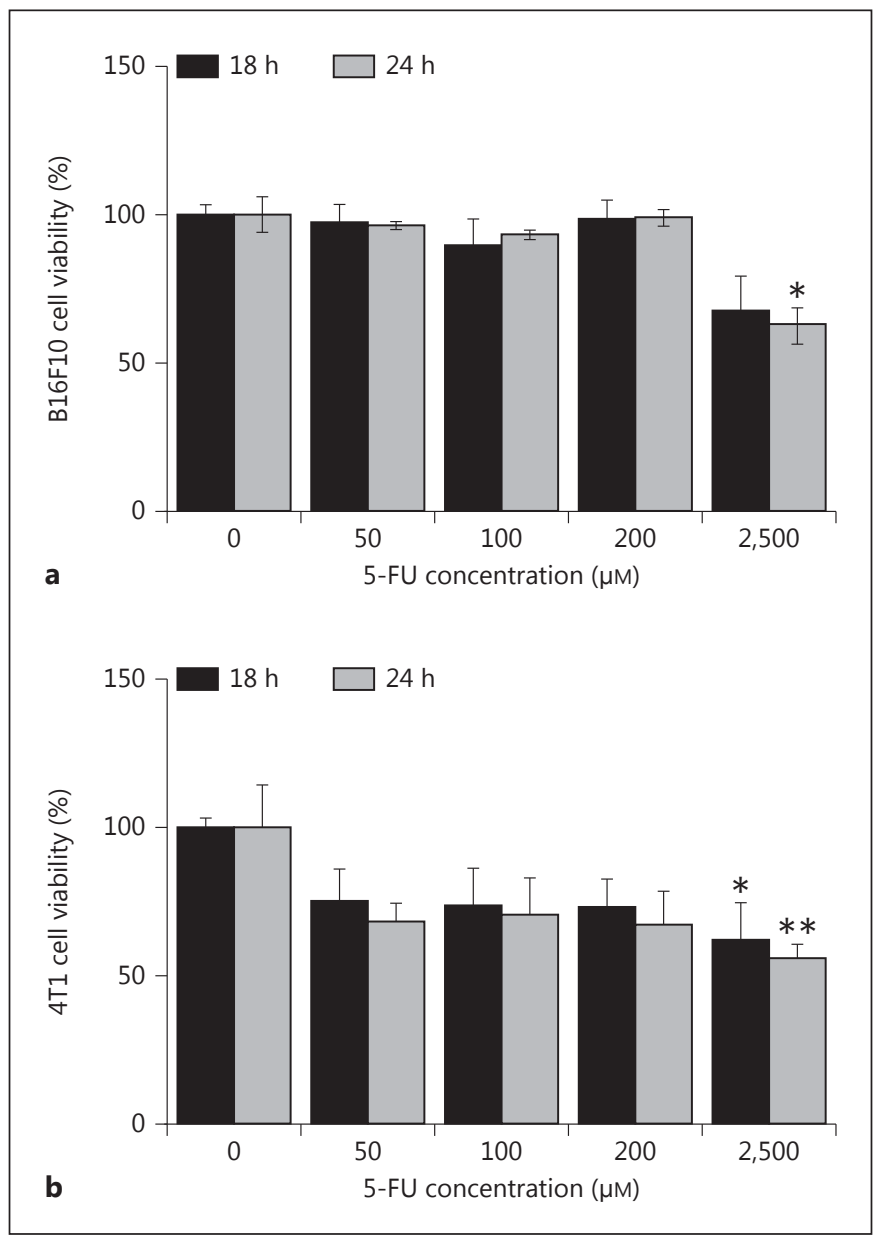

Fig. 1. Viability of tumor cell lines treated with various concentrations of 5-FU using MTT assay. B16F10 melanoma (a) and 4T1 mammary (b) cancer cell lines were treated with various concentrations of 5-FU (50, 100, 200 and 2,500 $\mu \mathrm{M})$ for 18 and $24 \mathrm{~h}$ and viability was determined by MTT assay. The percentages of cell viability were obtained by calculating the ratio of the absorbance of 5-FU-treated samples to untreated control samples in the identical time. Results were obtained from 3 independent experiments in triplicate for every cell line. ${ }^{*} \mathrm{p} \leq 0.05,{ }^{* *} \mathrm{p} \leq 0.01$.

$2,500 \mu \mathrm{M}$ of 5-FU, known to be a cytotoxic concentration, was significantly reduced ( $<25 \%$, data not shown).

Next, to determine the likely toxic effects of 5-FU on tumor cell lines, B16F10 melanoma and 4T1 mammary tumor cell lines were treated with indicated doses of 5-FU for 18 and $24 \mathrm{~h}$ and the viability of the cells was analyzed with MTT assay. After 18 and $24 \mathrm{~h}$ of treatment, the viability of both B16F10 and 4T1 tumor cell lines was not significantly reduced by using 5-FU up to $200 \mu \mathrm{M}$ (i.e. low concentrations; $\mathrm{p}=0.11$ ), while at a high concentration of $2,500 \mu \mathrm{M}$, there was a significant reduction in viability of both of these tumor cell lines (fig. 1). These results 

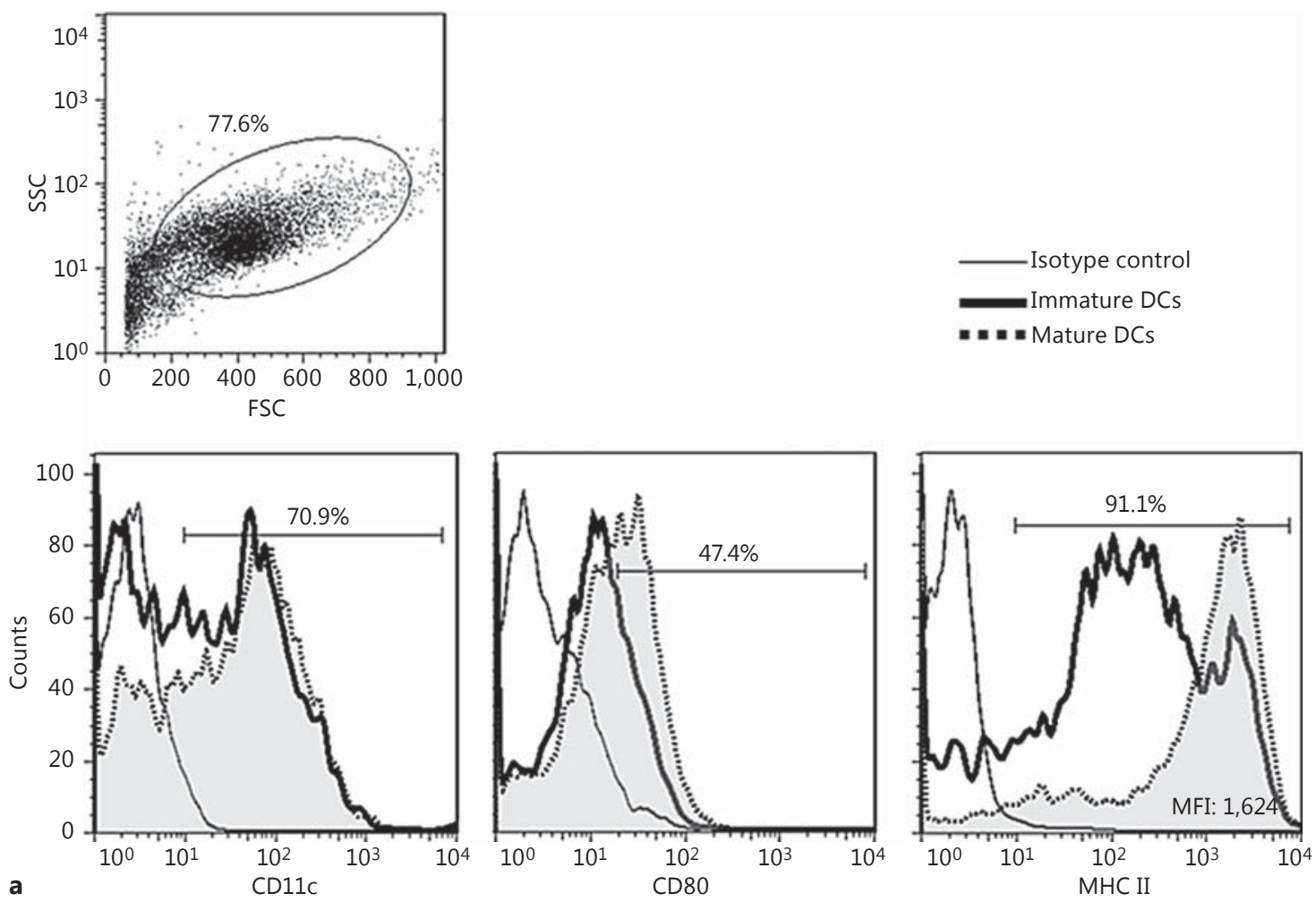

Isotype control
5-FU-treated mature DCs
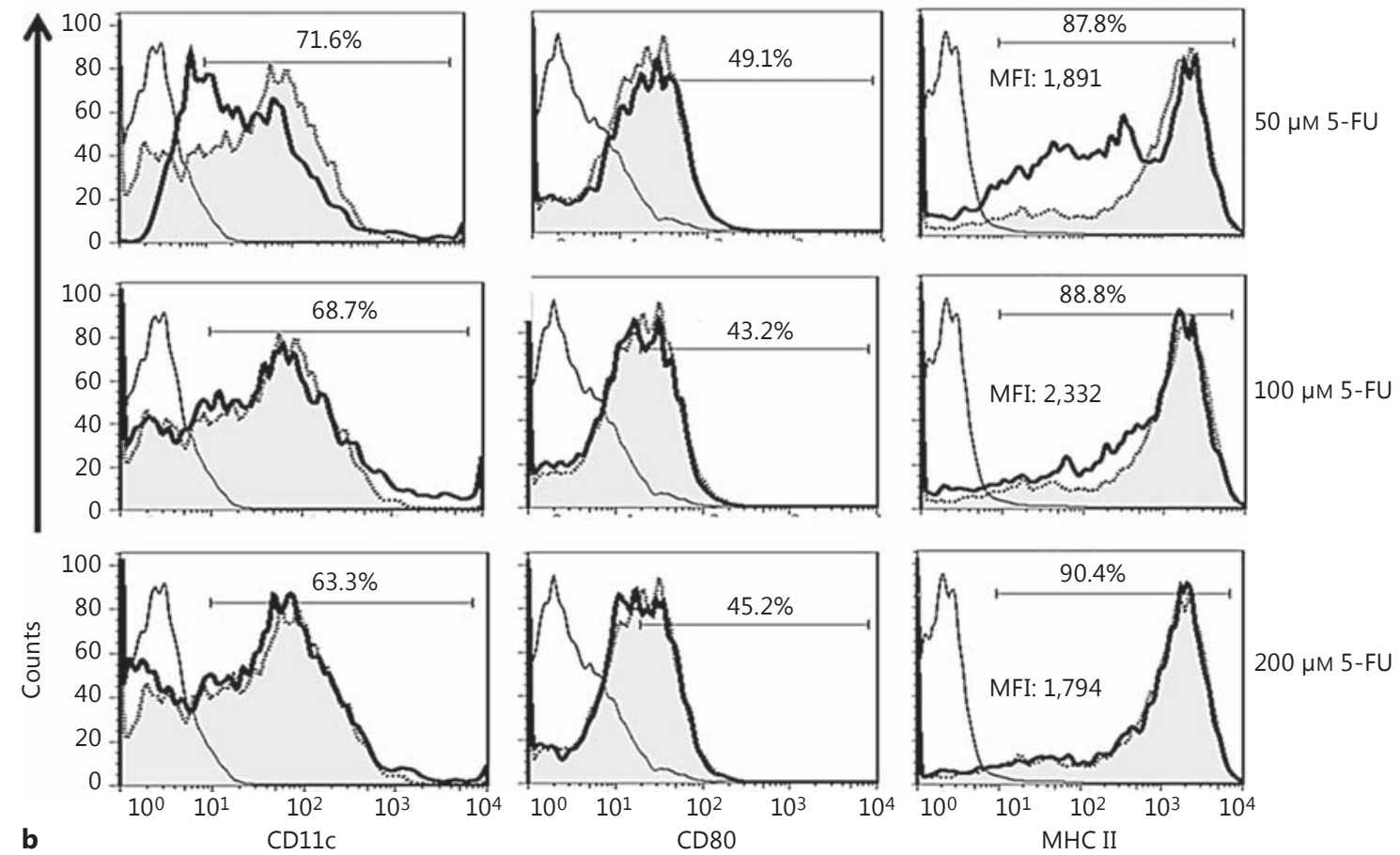

(For legend and parts $c-d$ see next page.)

5-FU Has No Adverse Effects on Maturation of DCs
Int Arch Allergy Immunol 2015;168:122-130 DOI: $10.1159 / 000442290$ 


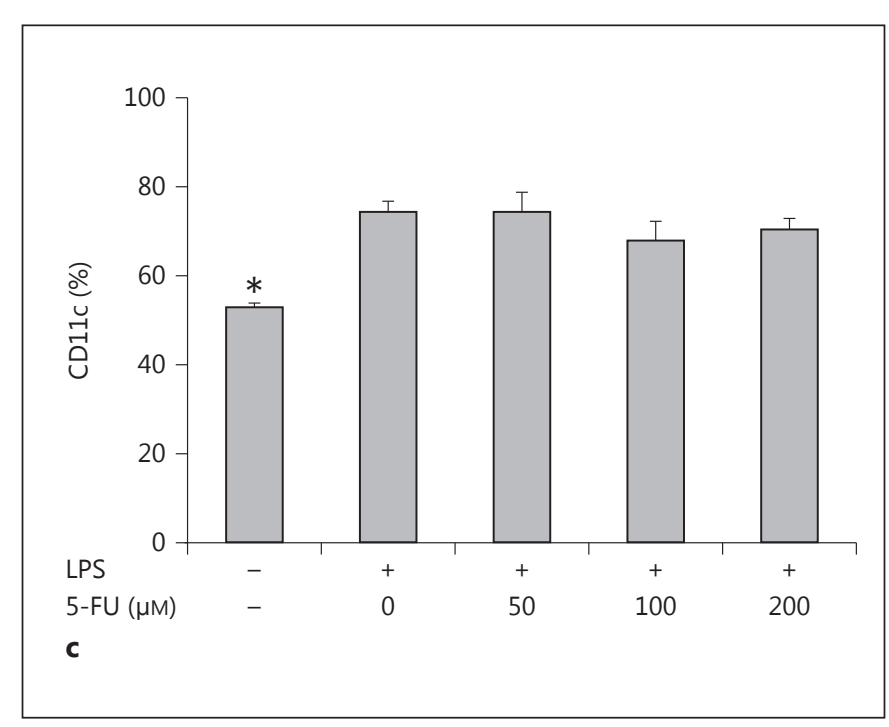

Fig. 2. Flow cytometric analyses of phenotypic markers of BMDCs treated with low concentrations of 5-FU. BM-DCs were generated from BM precursors in the presence of GM-CSF and IL-4 (Materials and Methods). 5-FU in different concentrations was added to the culture on day 6 simultaneously with/without LPS as a maturation factor. DCs were harvested on day 7 and analyzed using FACSCalibur and FlowJo software. The percentages of expression levels of CD11c and CD80, the percentage and MFI of MHC class II on untreated LPS-mature DCs vs. immature DCs (a) and mature DCs treated with various low concentrations of 5-FU (b) and the mean \pm SEM of CD11c (c), CD80 (d) and MFI of MHC II (e) are shown. The flow cytometry analyses of 1 experiment are shown as histogram plots. The statistical analyses are from 3 independent experiments. ${ }^{*} \mathrm{p} \leq 0.05,{ }^{* *} \mathrm{p} \leq 0.01$.

demonstrate that indicated low doses of 5-FU do not inhibit the proliferation of tumor cell lines and DC viability.

\section{Low Concentrations of 5-FU Fail to Reduce the}

Expression Level of Differentiation and Maturation

Markers of BM-DCs

To determine whether 5-FU in low, noncytotoxic concentrations influences the differentiation and maturation surface markers on DCs, the expression levels of CD11c, CD80 and MHC class II molecules on 5-FU-treated and untreated mature DCs versus untreated immature DCs were analyzed using flow cytometry. The results for mature versus immature untreated DCs (showing the process of DC maturation) and mature DCs treated with indicated low concentrations of 5-FU are represented in
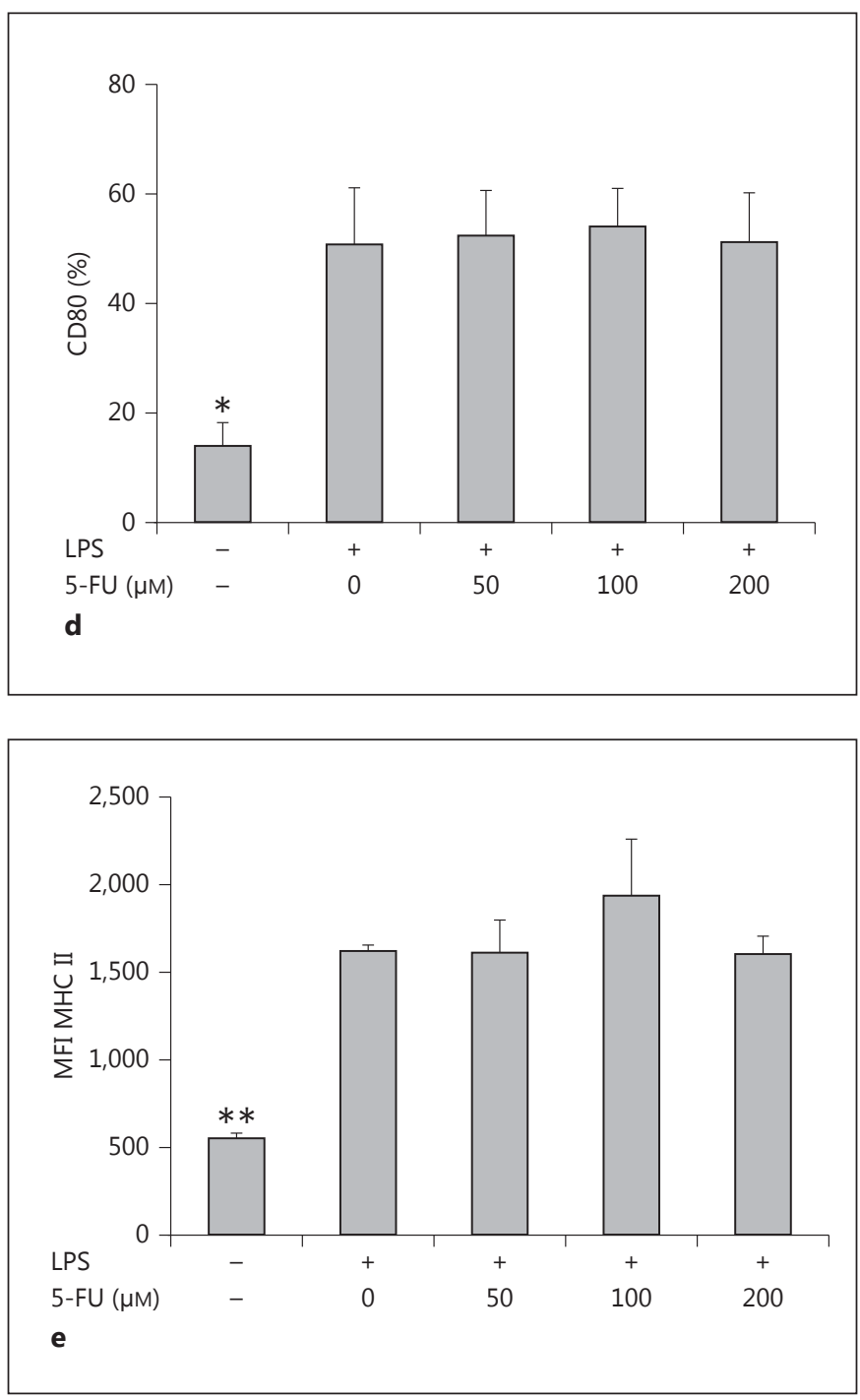

figure 2a, b. Although the expressions of CD11c and CD80 were significantly increased after LPS maturation in all mature DCs versus immature DCs (CD11c: $p=0.02$ and CD80: $p=0.03$ ), the expression of these markers slightly altered in 5-FU-treated mature DCs when compared with the untreated cells; this was not significant (CD11c: $\mathrm{p}=0.5$ and CD80: $\mathrm{p}=0.9$; fig. $2 \mathrm{c}, \mathrm{d}$ ). Moreover, the MFI of MHC class II was intensively increased in untreated and 5-FU-treated mature DCs when compared with untreated immature DCs $(\mathrm{p}=0.06)$, but the $5-\mathrm{FU}$ treatments hardly affected the MFI of MHC class II in comparison with mature untreated DCs; this was not statistically significant $(\mathrm{p}=0.5$; fig. $2 \mathrm{e})$. These results show that low, noncytotoxic concentrations of 5 -FU do not inhibit the differentiation and maturation of DCs in vitro. 


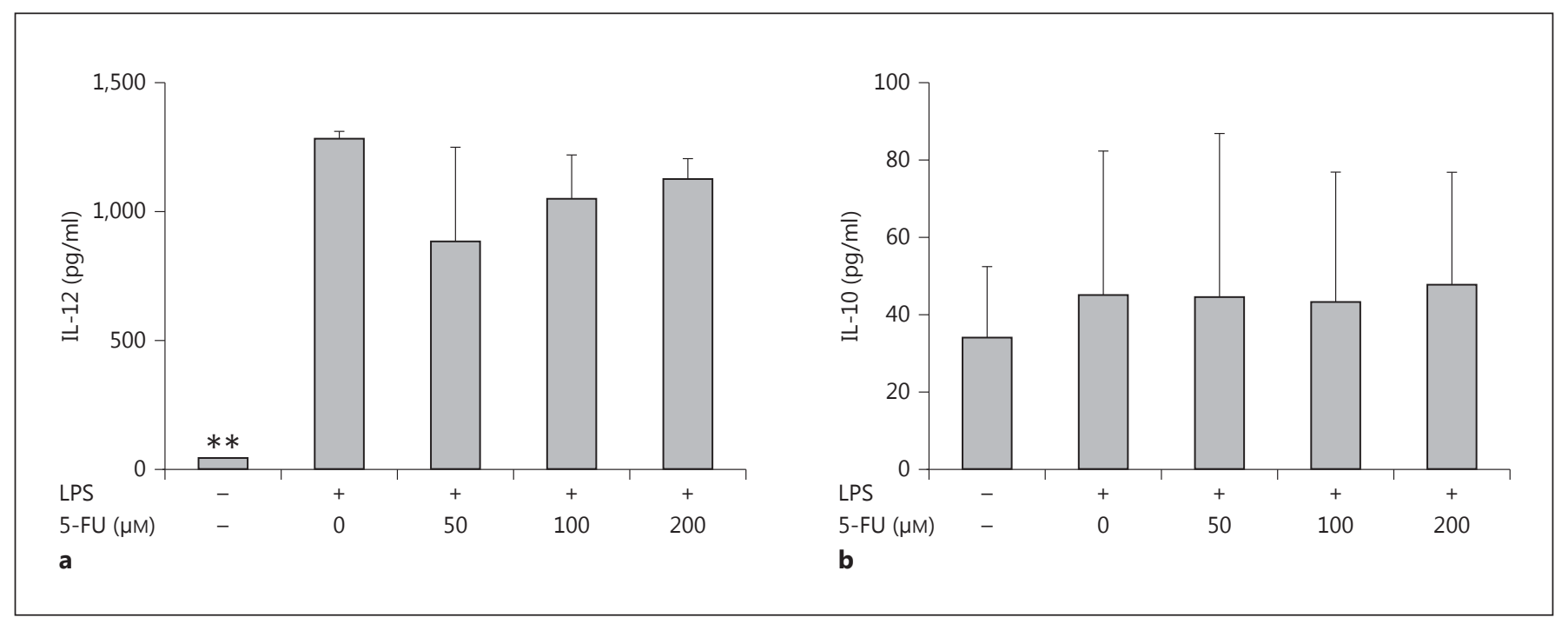

Fig. 3. Low doses of 5-FU do not affect cytokine production by BM-DCs. Before harvesting on day 7, the supernatants from the culture of immature DCs (as a negative control) and 5-FU-treated or untreated LPS-mature DCs were collected and analyzed using
ELISA. Graphs represent the mean \pm SEM of the concentration of IL-12 (a) and IL-10 (b) in the supernatants of the abovementioned DC cultures. Data are from 3 independent experiments. ${ }^{* *} \mathrm{p} \leq$ 0.01 .
The Noninhibitory Effects of Low Concentrations of 5-FU on the Production of IL-12 and IL-10 by $B M-D C s$

Cytokine production represents the potency of DCs as the professional APC to activate T cells. To describe the noninhibitory effects of low doses of 5-FU on the function of DCs, the concentration of IL-12 and IL-10 in the supernatant of untreated or treated DCs with different low doses of 5-FU was evaluated. Although IL-12 production in untreated immature DCs was at a significantly low level when compared with mature untreated and 5-FUtreated DCs ( $p=0.006)$, various low doses of 5-FU slightly decreased IL-12 production in mature DCs; this was not significant ( $p=0.8$; fig. $3 a$ ). Moreover, our data in IL-10 concentration readily confirmed that low doses of 5 -FU did not change the production level of IL-10 ( $\mathrm{p}=$ 0.9 ; fig. $3 \mathrm{~b}$ ). These results suggest that the immunostimulatory function of mature DCs was not inhibited by low, noncytotoxic concentrations of 5-FU.

\section{Effect of Low Concentrations of 5-FU on the}

Antigen-Presenting Function of BM-DCs

Finally, to assess the immunostimulatory capacity of 5-FU-treated DCs, the antigen-specific T cell proliferation was tested in a DC/T cell coculture. Whereas $\mathrm{T}$ cell proliferation was not significantly altered in the presence of $50 \mu \mathrm{M} 5$-FU-treated DC in comparison with untreated mature DCs in the coculture (65.4 vs. $69.9 \%$; fig. 4 a), a considerable increase in $\mathrm{T}$ cell proliferation was seen at higher concentrations of 5 -FU $(82.8 \%$ in $100 \mu \mathrm{M}$ and $84.3 \%$ in $200 \mu \mathrm{M}$ vs. $69.9 \%$ in untreated mature DCs; fig. $4 \mathrm{~b})$, but these differences were not significant ( $\mathrm{p}=0.6$; fig. 4c). This result suggests that 5-FU at low, noncytotoxic doses could, indirectly, act as an adjuvant rather than an inhibitor for DC activation.

\section{Discussion}

Low concentrations of many chemotherapeutic drugs have been shown to induce antitumor immune responses through various mechanisms like the targeting of immunosuppressive cells that substantially impede the immunotherapeutic activities of DC vaccines [17-20]. Among these agents, 5-FU in low concentrations has attracted much attention because of the increase in antitumor immune responses by selectively depleting immunosuppressive cells with myeloid lineages with the least adverse effects on the frequency of other immune cells [13]. Thus, combining DC immunotherapy and low concentrations of 5-FU could be an alternative approach for cancer treatment. However, 5-FU at low doses, due to its myeloid origin, might directly deplete injected DCs, thereby negatively modulating the immunotherapeutic functions of 
Fig. 4. 5-FU in low concentrations did not affect the capacity of DCs to proliferate antigen-specific $\mathrm{T}$ cells. Untreated immature and mature DCs or 5-FU-treated mature DCs preloaded with 4T1 mouse mammary tumor cell line lysate $(100 \mu \mathrm{g} / \mathrm{ml})$ were cocultured with autologous CFSE-stained T cells induced with $4 \mathrm{~T} 1$ lysate $(500 \mu \mathrm{g} / \mathrm{ml})$ in vivo and purified on a nylon wool column (DC/T cell ratio 5:1). After 5 days, $\mathrm{T}$ cell proliferation was assessed by CFSE dilution assay after gating on CD3+ cells in the lymphocyte population. The percentages of CFSE dilution representing $\mathrm{T}$ cell proliferation in the presence of untreated and 5-FU-treated mature DCs are shown in a and $\mathbf{b}$, respectively. $\mathbf{c}$ Bar graphs depict the mean \pm SEM of the percentage of $\mathrm{T}$ cell proliferation in the presence of untreated or 5-FU-treated mature DCs vs. untreated immature DCs from at least 3 independent experiments (in triplicate) for each group.
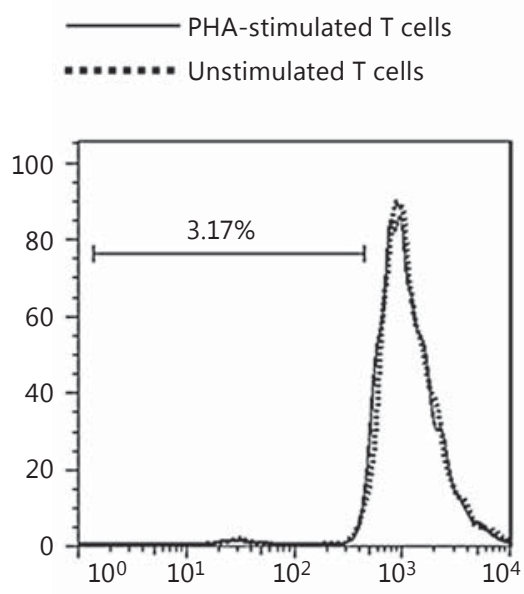

a

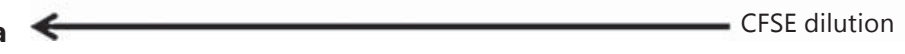

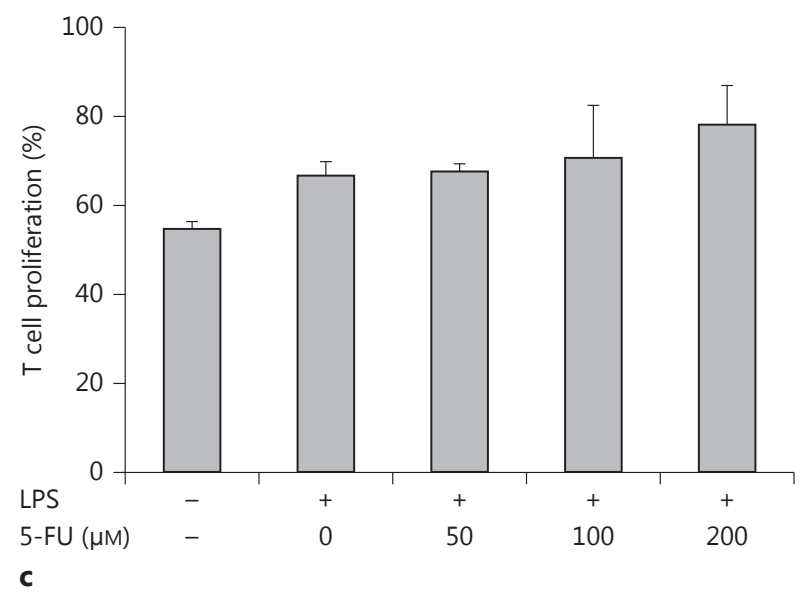


BM-DCs. Therefore, we examined the in vitro modulatory effects of low, noncytotoxic concentrations of 5-FU on maturation and the immunostimulatory functions of BM-DCs.

We determined, for the first time, that 5-FU in low, non-cytotoxic concentrations had no adverse effects on the expression of CD11c as differentiation marker. Data obtained in previous studies indicated that low doses of several chemotherapeutic drugs upregulate $\mathrm{CD} 11 \mathrm{c}$ when used on the first day of DC culture, in order to detect the immunostimulatory properties of low concentrations of these drugs $[18,20]$. In our study, the modulatory effects of low concentrations of 5-FU were evaluated during the last $18 \mathrm{~h}$ of DC culture.

The expression level of MHC class II and costimulatory molecules like CD80 represents the ability of DCs as professional APCs to activate T cells [3]. Therefore, these are the key activation markers required to evaluate the modulatory effects of low, noncytotoxic concentrations of chemotherapeutic drugs on BM-DCs $[20,21]$. We found that low concentrations of 5-FU did not inhibit the expression of MHC II and CD80. Our results are the first where the modulatory effects of these doses on DC activation phenotypes were evaluated in vitro, and are consistent with previous results with other chemotherapeutic drugs [18-20]. Besides, in vivo experiments confirm that a single systemic injection of a low, noncytotoxic dose of 5 -FU ( $50 \mathrm{mg} / \mathrm{kg}$ ) did not alter the expression of CD40 and CD86 on the spleen-resident DCs of normal mice [13].

Apart from costimulatory expression, the production of IL-12 by DCs is the other essential signal showing the optimal capacity of DCs for T cell activation [22, 23]. We found no reduction in IL-12 production of BM-DCs treated with low, noncytotoxic doses of 5-FU. Moreover, increased levels of autocrine IL-10 in BM-DCs represent their functional alterations and block the maturation process by interfering with the upregulation of costimulatory molecules and the production of IL-12, thereby limiting the ability of DCs to initiate a potent $\mathrm{T}$ cell response. We also detected no drastic increase in the level of IL-10. This result became more significant when it was revealed that low doses of 5-FU acted as an inducer of DCs to proliferate $\mathrm{T}$ cells more effectively than untreated LPS-mature DCs. Our data confirm the finding of previous studies on mice and humans that low doses of certain chemotherapeutic drugs play a stimulatory role to enhance DC function [18-20].

The noninhibitory activities of low concentrations of 5 -FU were also shown in an in vivo study, where intraperitoneal injection of 5-FU and cisplatin in low, noncy- totoxic doses $(10 \mathrm{mg} / \mathrm{kg}$ of $5-\mathrm{FU}$ and $0.1 \mathrm{mg} / \mathrm{kg}$ of cisplatin) delayed the MC38 tumor growth for a limited period of time. These concentrations could induce antitumor immune responses and increase the survival of mice when combined with DC vaccines [24]. The cumulative effects of incorporating low doses of cytotoxic agents into DC vaccines have also been reported for other drugs. For instance, an intratumoral DC vaccine strongly decreased mouse lung carcinoma growth and increased IFN- $\gamma$ production by tumor-specific lymphocytes after the administration of low concentrations of paclitaxel [21]. Furthermore, in melanoma patients, metronomic administration of low doses of temozolomide before $\mathrm{DC}$ vaccination reduced the number of circulating Foxp3+ regulatory $\mathrm{T}$ cells [25]. Thus, it seems that low concentrations of 5-FU might not alter the functional activity of exogenous DCs.

Collectively, our findings demonstrate that low, noncytotoxic concentrations of 5-FU have no adverse effects on the functional activities of DCs. These low concentrations of 5-FU are at present confined to in vivo studies, but a combination of low, noncytotoxic doses of 5-FU, as single or multiple administrations, and DC vaccine immunotherapy might achieve better tumor control and more effective anticancer immune responses.

\section{Acknowledgements}

The main part of this work was financially supported by Iran National Science Foundation (grant No. 90007957) and the remainder by the Isfahan University of Medical Sciences (grant No. 113946). We wish to thanks Dr. Behrouz Nikbin for his kindly paper revision.

References

Int Arch Allergy Immunol 2015;168:122-130 129
1 Rosenberg SA, Yang JC, Restifo NP: Cancer immunotherapy: moving beyond current vaccines. Nat Med 2004;10:909-915.

2 Steinman RM, Banchereau J: Taking dendritic cells into medicine. Nature 2007;449:419426.

3 Palucka K, Banchereau J: Cancer immunotherapy via dendritic cells. Nat Rev Cancer 2012;12:265-277.

4 Chang AE, Redman BG, Whitfield JR, Nickoloff BJ, Braun TM, Lee PP, Geiger JD, Mule JJ: A phase I trial of tumor lysate-pulsed dendritic cells in the treatment of advanced cancer. Clin Cancer Res 2002;8:1021-1032.

5 Gitlitz BJ, Belldegrun AS, Zisman A, Chao DH, Pantuck AJ, Hinkel A, Mulders P, Moldawer N, Tso CL, Figlin RA: A pilot trial of tumor lysate-loaded dendritic cells for the treatment of metastatic renal cell carcinoma. J Immunother 2003;26:412-419.
5-FU Has No Adverse Effects on

Maturation of DCs 
6 Gabrilovich DI, Nagaraj S: Myeloid-derived suppressor cells as regulators of the immune system. Nat Rev Immunol 2009;9:162-174.

7 Browder T, Butterfield CE, Kraling BM, Shi B, Marshall B, O'Reilly MS, Folkman J: Antiangiogenic scheduling of chemotherapy improves efficacy against experimental drug-resistant cancer. Cancer Res 2000;60:18781886.

8 Klement G, Baruchel S, Rak J, Man S, Clark K, Hicklin DJ, Bohlen P, Kerbel RS: Continuous low-dose therapy with vinblastine and VEGF receptor-2 antibody induces sustained tumor regression without overt toxicity. J Clin Invest 2000;105:R15-R24.

9 Suzuki E, Kapoor V, Jassar AS, Kaiser LR, Albelda SM: Gemcitabine selectively eliminates splenic GR-1+/CD11b+ myeloid suppressor cells in tumor-bearing animals and enhances antitumor immune activity. Clin Cancer Res 2005;11:6713-6721.

10 Ghiringhelli F, Menard C, Puig PE, Ladoire S, Roux S, Martin F, Solary E, Le Cesne A, Zitvogel L, Chauffert B: Metronomic cyclophosphamide regimen selectively depletes $\mathrm{CD} 4+\mathrm{CD} 25+$ regulatory $\mathrm{T}$ cells and restores $T$ and NK effector functions in end-stage cancer patients. Cancer Immunol Immunother 2007;56:641-648.

11 Tongu M, Harashima N, Monma H, Inao T, Yamada T, Kawauchi H, Harada M: Metronomic chemotherapy with low-dose cyclophosphamide plus gemcitabine can induce anti-tumor $\mathrm{T}$ cell immunity in vivo. Cancer Immunol Immunother 2013;62:383-391.
12 Hasnis E, Alishekevitz D, Gingis-Veltski S, Bril R, Fremder E, Voloshin T, Raviv Z, Karban A, Shaked Y: Anti-BV8 antibody and metronomic gemcitabine improve pancreatic adenocarcinoma treatment outcome following weekly gemcitabine therapy. Neoplasia 2014; 16:501-510.

13 Vincent J, Mignot G, Chalmin F, Ladoire S, Bruchard M, Chevriaux A, Martin F, Apetoh L, Rebe C, Ghiringhelli F: 5-Fluorouracil selectively kills tumor-associated myeloid-derived suppressor cells resulting in enhanced $\mathrm{T}$ cell-dependent antitumor immunity. Cancer Res 2010;70:3052-3061.

14 Brazowski E, Eytan K, Eisenthal A: In vitro modulation of interleukin-2-mediated human peripheral mononuclear cell proliferation and antitumor cytotoxicity by 5 -fluorouracil. Anticancer Res 2007;27:4135-4141.

15 Inaba K, Inaba M, Romani N, Aya H, Deguchi M, Ikehara S, Muramatsu S, Steinman RM: Generation of large numbers of dendritic cells from mouse bone marrow cultures supplemented with granulocyte/macrophage colony-stimulating factor. J Exp Med 1992;176: 1693-1702.

16 Ge Q, Palliser D, Eisen HN, Chen J: Homeostatic $\mathrm{T}$ cell proliferation in a T cell-dendritic cell coculture system. Proc Natl Acad Sci USA 2002;99:2983-2988.

17 Emens LA: Chemoimmunotherapy. Cancer J 2010;16:295-303.

18 Kaneno R, Shurin GV, Tourkova IL, Shurin MR: Chemomodulation of human dendritic cell function by antineoplastic agents in low noncytotoxic concentrations. J Transl Med 2009;7:58.

19 John J, Ismail M, Riley C, Askham J, Morgan R, Melcher A, Pandha H: Differential effects of paclitaxel on dendritic cell function. BMC Immunol 2010;11:14.
20 Shurin GV, Tourkova IL, Kaneno R, Shurin MR: Chemotherapeutic agents in noncytotoxic concentrations increase antigen presentation by dendritic cells via an IL-12-dependent mechanism. J Immunol 2009;183:137144 .

21 Zhong H, Han B, Tourkova IL, Lokshin A, Rosenbloom A, Shurin MR, Shurin GV: Lowdose paclitaxel prior to intratumoral dendritic cell vaccine modulates intratumoral cytokine network and lung cancer growth. Clin Cancer Res 2007; 13:5455-5462.

22 Kalinski P: Dendritic cells in immunotherapy of established cancer: roles of signals 1,2, 3 and 4. Curr Opin Investig Drugs 2009;10: 526-535.

23 Mescher MF, Curtsinger JM, Agarwal P, Casey KA, Gerner M, Hammerbeck CD, Popescu F, Xiao Z: Signals required for programming effector and memory development by CD8+ T cells. Immunol Rev 2006;211:8192.

24 Tanaka F, Yamaguchi H, Ohta M, Mashino K, Sonoda H, Sadanaga N, Inoue H, Mori M: Intratumoral injection of dendritic cells after treatment of anticancer drugs induces tumorspecific antitumor effect in vivo. Int J Cancer 2002;101:265-269.

25 Ridolfi L, Petrini M, Granato AM, Gentilcore G, Simeone E, Ascierto PA, Pancisi E, Ancarani V, Fiammenghi L, Guidoboni M, de Rosa F, Valmorri L, Scarpi E, Nicoletti SV, Baravelli S, Riccobon A, Ridolfi R: Low-dose temozolomide before dendritic-cell vaccination reduces (specifically) $\mathrm{CD} 4+\mathrm{CD} 25++\mathrm{FOXp} 3+$ regulatory T-cells in advanced melanoma patients. J Transl Med 2013;11:135. 